\section{La prevención de la influenza: recomendaciones para la temporada de 2005-2006 1}

\author{
Eloísa Le Riverend²
}

Palabras clave: influenza, vacunación, pautas prácticas.

\footnotetext{
Basado en: Harper SA, Fukuda K, Uyeki TM, Cox NJ, Bridges CB. Prevention and control of influenza. Recommendations of the Advisory Committee on Immunization Practices (ACIP). MMWR Recomm Rep. 2005;54(Early release):1-40.

2 Grupo Asesor, Instituto Finlay, Ciudad de La Habana, Cuba. La correspondencia debe dirigirse a: Instituto Finlay, avenida 27 No. 19805, Reparto La Coronela, La Lisa, Ciudad de La Habana, Cuba. Coreo electrónico: lochy@infomed.sld.cu
}

La influenza constituye un grave problema mundial de salud debido a las epidemias y pandemias que causa periódicamente. En niños y adultos sanos, la enfermedad no es grave y puede durar pocos días, aunque la debilidad y la depresión pueden persistir durante semanas. Las tasas de infección son mayores en niños de todas las edades, pero las complicaciones graves y la muerte ocurren con mayor frecuencia en personas de 65 años o más y en niños menores de 2 años, así como en personas con trastornos inmunitarios o del aparato respiratorio o cardiovascular, independientemente de la edad (1).

La diseminación de la enfermedad es muy rápida, pues el contagio interpersonal ocurre mediante partículas virales presentes en el aerosol que se forma cuando una persona infectada habla, tose o estornuda. Este tipo de diseminación es muy eficaz, por lo que en poblaciones cerradas y de alta densidad es frecuente encontrar tasas de ataque de hasta $90 \%$.

Los virus de la influenza A, B y C son virus pleomórficos de la familia Orthomyxoviridae. Tienen un tamaño de alrededor de $90 \mathrm{~nm}$, con una cápside nuclear de simetría helicoidal dentro de una envoltura lipídica, a cuya superficie externa se adhieren espículas de glicoproteínas de dos tipos - hemaglutininas y neuroaminidasas- que sufren variación independiente. Los tres tipos de virus de la influenza son antigénicamente diferentes, aunque los virus A y B son idénticos desde el punto de vista morfológico. El virus de la influenza A es el principal causante de las grandes epidemias debido a su gran variabilidad antigénica, mientras que el B causa epidemias más limitadas y el C no ha se asociado con epidemias. Cuando aparece un cambio en la estructura antigénica del virus circulante, la inmunidad existente y las vacunas fabricadas se vuelven ineficaces y se producen las epidemias. Las cepas del tipo A se clasifican en subtipos de acuerdo con el tipo de hemaglutinina y de neuroaminidasa que poseen (H1N1, H3N2, etc.). Se han aislado cepas del tipo A en varias especies de animales, como aves, cerdos y equinos. Aunque normalmente existen barreras para la transmisión entre especies, se han aislado en virus de animales hemaglutininas y neuroaminidasas indistinguibles de las encontradas en los virus aislados en seres humanos (2).

La inmunidad contra los antígenos de superficie, particularmente la hemaglutinina, disminuye 
la probabilidad de infección y la gravedad de la enfermedad si esta llega a ocurrir. Los anticuerpos producidos contra un tipo o subtipo del virus de la influenza confieren poca o ninguna protección contra otro tipo o subtipo. Además, los anticuerpos contra una variante antigénica del virus no protegen totalmente contra una nueva variante del mismo tipo o subtipo.

La vacunación es un elemento usado para prevenir y controlar la enfermedad en la población en general, pero está especialmente indicada para los grupos en riesgo de sufrir complicaciones y sus contactos. La inmunidad adquirida, ya sea de forma natural o por vacunación, es de corta duración; ello unido a la gran variación del virus, impide predecir qué cepas circularán cada año. Una vez aisladas las cepas circulantes, se confeccionan las vacunas que se administrarán ese año (3). Cuando las cepas vacunales y epidémicas se corresponden bien y se logran altas tasas de vacunación en personas recluidas en instituciones sanitarias y en el personal que las atiende, se provoca la llamada inmunidad de "rebaño" y se reduce el riesgo de que surjan brotes.

Recientemente el Comité Asesor en Prácticas de Inmunización de los Estados Unidos de América publicó las recomendaciones actualizadas para la prevención y el control de la influenza en la temporada de 2005-2006. Muchas de estas directrices son de interés para los países de la Región, en particular las relativas a la vacunación, ya que constituyen el pilar principal para la prevención y el control de esta enfermedad.

\section{GRUPOS QUE DEBERÁN VACUNARSE}

\section{Grupos de vacunación prioritaria}

Para reducir el efecto de la influenza lo mejor es vacunar a las personas en alto riesgo de sufrir complicaciones a causa de la infección y a sus contactos cercanos cada año, antes de la temporada de mayor circulación del virus.

Personas con mayor riego de complicaciones. Se recomienda la aplicación de la vacuna a base de virus inactivado a las personas que se encuentran en mayor riesgo de sufrir complicaciones en caso de infección (cuadro 1).

Personas entre 50 y 64 años de edad. Se recomienda vacunar a este grupo de población por ser el que contiene una mayor proporción de personas en alto riesgo de sufrir complicaciones debido a la infección con el virus de la influenza.
CUADRO 1. Personas en mayor riesgo de sufrir complicaciones a raíz de influenza

- Personas de 65 años o más

- Personas que residen en hogares y otras instituciones de asistencia prolongada para problemas crónicos de salud

- Adultos y niños con trastornos crónicos del sistema respiratorio o cardiovascular, incluida el asma (la hipertensión no se considera factor de alto riesgo)

- Adultos y niños que hayan necesitado seguimiento médico u hospitalización el año anterior debido a enfermedades metabólicas crónicas (como la diabetes mellitus), disfunción renal, hemoglobinopatías o inmunosupresión (entre ellas la causada por medicamentos o por el virus de la inmunodeficiencia humana [VIH])

- Adultos y niños con cualquier afección que pueda comprometer la función respiratoria o la eliminación de las secreciones o aumentar el riesgo de aspiración (disfunción cognoscitiva, lesiones de la médula espinal, convulsiones $u$ otros trastornos neuromusculares)

- Niños y adolescentes entre 6 meses y 18 años de edad que reciben tratamiento prolongado con aspirina y que pueden estar en riesgo de sufrir el síndrome de Reye

- Las mujeres que esperan quedar embarazadas durante la temporada de influenza

- Niños entre 6 y 23 meses de edad

Personas que puedan transmitir la influenza a otras en alto riesgo de sufrir complicaciones. Las personas con infección clínica o subclínica pueden transmitir el virus de la influenza a personas en alto riesgo de sufrir complicaciones. Disminuir la transmisión de la influenza de los cuidadores y contactos domésticos a las personas en alto riesgo de sufrir complicaciones podría reducir la mortalidad por esta enfermedad. La vacuna con virus vivos atenuados contra la influenza ha permitido reducir el número de casos con enfermedades respiratorias agudas entre los contactos de los vacunados, así como el número de días de trabajo perdidos y de visitas del personal de salud. En este grupo se encuentran los empleados de los hogares y residencias de personas en grupos de alto riesgo, las personas que atienden a estas últimas en sus hogares y los contactos domésticos de las personas en alto riesgo (entre ellas los niños). Como los niños entre 0 y 23 meses de edad tienen un elevado riesgo de hospitalización por influenza, se recomienda vacunar a sus contactos domésticos cercanos y a sus cuidadores, particularmente en el caso de niños de 0 a 6 meses de edad, para los cuales no hay ninguna vacuna aprobada.

Trabajadores de la salud. Todos los trabajadores de la salud deben vacunarse anualmente contra la influenza. Esto protegerá no solo a los trabajadores mismos, sino también a sus pacientes y a la co- 
munidad. Las tasas de vacunación en trabajadores de la salud deben calcularse e informarse periódicamente. Algunos estudios indican que la vacunación del personal de salud está asociada con la disminución de la mortalidad en pacientes y con una menor frecuencia de aparición de brotes de influenza en los hospitales donde trabajan personas que no han sido vacunadas.

\section{Información adicional sobre la vacunación de poblaciones específicas}

Otros grupos poblacionales también pueden beneficiarse de recibir la vacuna contra la influenza.

Mujeres embarazadas. Las mujeres que esperan quedar embarazadas durante la temporada de influenza deben vacunarse, sin importar en qué trimestre de la gestación lo hagan. Un estudio realizado en unas 2000 mujeres embarazadas no reveló efectos adversos asociados con la vacuna.

Niños pequeños sanos. Se debe vacunar a todos los niños de 6 a 23 meses de edad, ya que tienen un mayor riesgo de hospitalización por influenza. Actualmente no hay vacunas inactivadas aprobadas para niños menores de 6 meses - el grupo de mayor riesgo de padecer complicaciones por la infección-, por lo que se debe vacunar a sus contactos.

Personas infectadas por el virus de la inmunodeficiencia humana (VIH). Aunque la información con respecto a la frecuencia y la gravedad de la influenza y los beneficios de la vacunación en personas con infección por el VIH es escasa, un estudio retrospectivo determinó que el riesgo de hospitalización por trastornos cardiopulmonares entre mujeres jóvenes y de mediana edad portadoras del VIH era más alto en las temporadas de influenza que en otros momentos del año.

La vacuna inactivada contra la influenza produce altos títulos de anticuerpos en las personas infectadas por el VIH que presenten pocos síntomas de sida y elevación de los linfocitos CD4+. Un ensayo aleatorio con placebo demostró que la vacunación es eficaz para prevenir la influenza en personas infectadas por el VIH. Como la influenza puede ser una enfermedad grave y la vacunación con el virus inactivado puede producir títulos suficientes de anticuerpos protectores, la vacunación beneficia a las personas infectadas por el VIH.

Madres lactantes. La vacuna contra la influenza es inocua para las madres que amamantan a sus hijos. La lactancia no menoscaba la respuesta inmunitaria ni constituye una contraindicación para la vacunación.
Viajeros. En el trópico, el riesgo de contraer influenza se mantiene durante todo el año. En los países de clima templado del hemisferio norte, la influenza ocurre mayormente entre diciembre y principios de marzo, mientras que en los países templados del hemisferio sur la frecuencia aumenta entre abril y octubre. Por lo tanto, el riesgo de exposición al virus dependerá del momento del año y del lugar de destino del viajero. Los habitantes de países templados que no han recibido la vacuna durante la temporada actual deben vacunarse si viajan a países con mayor actividad de influenza, al trópico o en grupos. No existen datos sobre los posibles beneficios de una revacunación antes de viajar en el verano. Las personas de 50 años o más con alguno de los factores de riesgo discutidos más arriba deben consultar a sus médicos antes de viajar en el verano.

Población en general. Además de los grupos para los cuales se recomienda la vacunación anual, en los Estados Unidos de América está establecido que los médicos deben administrar la vacuna contra la influenza a cualquier persona que desee reducir la probabilidad de enfermar o de trasmitir la influenza a otros en caso de infectarse. Las personas que prestan servicios comunitarios esenciales deben vacunarse para minimizar la probabilidad de interrumpir las actividades que realizan durante la temporada de brotes de influenza. Se debe estimular a los estudiantes que viven en dormitorios y a personas recluidas en instituciones para que se vacunen, a fin de reducir al mínimo la interrupción de sus actividades durante las epidemias.

\section{UTILIZACIÓN DE VACUNAS CON VIRUS VIVOS ATENUADOS E INACTIVADOS}

Tanto la vacuna a base de virus vivos atenuados como la elaborada con virus inactivados sirven para reducir el riesgo de infección por el virus de la influenza. El uso de la vacuna elaborada con virus vivos atenuados está aprobado para personas sanas de 5 a 49 años de edad. Por su parte, la vacuna de virus inactivados está aprobada para niños a partir de los 6 meses de nacidos y adultos, incluso los que tienen un alto riesgo de complicaciones. Ambas vacunas reducen el riesgo de infección y de contraer formas graves de la enfermedad y poseen similitudes y diferencias que se deben tener en cuenta.

Ambas vacunas contienen cepas virales que son antigénicamente equivalentes a las cepas recomendadas anualmente: dos cepas del virus de la influenza A (una H3N2 y una H1N1) y una del virus de la influenza B. Sin embargo, cada año puede ser necesario cambiar una o varias de las cepas empleadas, en dependencia de los resultados de la vigi- 
lancia epidemiológica mundial y de la aparición de nuevas cepas. Los virus empleados para fabricar ambas vacunas se cultivan en huevos. Para lograr una protección óptima contra la infección por virus de la influenza, las vacunas se deben administrar anualmente.

La vacuna a base de virus inactivados contiene virus muertos, mientras que la otra contiene virus vivos atenuados capaces de replicarse. Esta última se administra por vía nasal mediante un atomizador, mientras que la primera se inyecta por vía intramuscular. La vacuna a base de virus vivos es más costosa que la de virus inactivados, aunque la diferencia de precio se redujo durante la última temporada.

\section{Recomendaciones sobre la vacuna de virus inactivados}

La vacuna de virus inactivados contra la influenza no debe administrarse a personas que tienen hipersensibilidad anafiláctica a los huevos u otros componentes de la vacuna sin la aprobación de un médico. No obstante, las personas en alto riesgo de sufrir complicaciones si enferman de influenza pueden beneficiarse de la vacunación, por lo que en algunos casos podrían desensibilizarse antes de recibir la vacuna. No se debe vacunar a las personas con enfermedades febriles agudas hasta que los síntomas no cesen. Las enfermedades menores con o sin fiebre no son una contraindicación para la vacunación, particularmente en los niños con infección leve del árbol respiratorio superior o rinitis alérgica.

La dosificación de la vacuna de virus inactivados contra la influenza varía según el grupo de edad (cuadro 2). Se recomienda aplicarla por vía intramuscular. Cuando se informa a los pacientes acerca de los posibles efectos colaterales de la vacuna, se deberá recalcar que la vacuna solamente contiene virus muertos, por lo que no es infecciosa y no puede causar influenza, aunque después de la vacunación puede aparecer otra enfermedad respiratoria sin relación alguna con ese virus.

\section{Recomendaciones sobre la vacuna a base de virus vivos atenuados}

La vacuna elaborada con virus vivos atenuados es una opción que se tiene para vacunar a las personas sanas de 5 a 49 años de edad, incluso a los trabajadores de la salud, a personas que estén en contacto con grupos en alto riesgo de sufrir complicaciones y a personas que deseen evitar la enfermedad. Cuando no se disponga de suficiente cantidad de vacunas de virus inactivados, la vacuna a base de virus vivos ate-
CUADRO 2. Esquema de administración de la vacuna inactivada contra la influenza

- En niños menores de 9 años sin vacunar previamente, se recomiendan dos dosis con un mes de intervalo

- Los niños menores de 9 años que no recibieron la segunda dosis en una misma temporada, en la siguiente deben recibir solamente una dosis

- Los adultos deben vacunarse anualmente con la vacuna recomendada para ese año

nuados debe tratar de emplearse en las personas indicadas, para aumentar la disponibilidad de vacunas de virus inactivados que se utilizarán en personas de los grupos en alto riesgo. Entre las ventajas de la vacuna viva atenuada está su capacidad de inducir una fuerte respuesta inmunitaria — tanto sistémica como en las mucosas-, su facilidad de administración y la mayor aceptación de la vía nasal con respecto a la intramuscular. Sin embargo, hay casos en que no debe emplearse esta vacuna (cuadro 3 ).

Es preferible usar la vacuna de virus inactivados en los convivientes, trabajadores de la salud y otras personas que se encuentran en contacto con personas inmunosuprimidas. La recomendación se basa en el riesgo teórico de que se les pueda transmitir el virus vivo atenuado a estas personas. Si un trabajador de la salud recibe esta vacuna, deberá abstenerse de estar en contacto con personas inmunosuprimidas durante los siete días posteriores a la vacunación, aunque no es necesario que se abstengan de visitar a pacientes que no estén inmunosuprimidos.

Administración de la vacuna a base de virus vivos atenuados. Es probable que no sea posible evitar la

CUADRO 3. Personas que no se deben vacunar con la vacuna a base de virus vivos atenuados

- Niños menores de 5 años o adultos de 50 años o mása

- Personas con asma, enfermedad reactiva de las vías respiratorias u otros trastornos pulmonares o cardiovasculares crónicos; personas con enfermedades metabólicas (como la diabetes), disfunción renal o hemoglobinopatías; y personas con diagnóstico o síntomas de inmunodeficiencia o que reciben tratamiento con inmunosupresores ${ }^{a}$

- Niños o adolescentes que toman aspirina u otros salicilatos (por la asociación del síndrome de Reye con la infección por el virus natural de la influenza) ${ }^{\mathrm{a}}$

- Personas con antecedentes de síndrome de Guillain-Barré

- Mujeres embarazadas

- Personas con antecedentes de hipersensibilidad, en particular a cualquier componente de la vacuna de virus vivos atenuados o a los huevos

${ }^{a}$ Estas personas deben recibir la vacuna con virus inactivados. 
introducción del virus de la vacuna en el ambiente cuando se administra la vacuna a base de virus vivos atenuados. Se desconoce el riesgo de adquirir estos virus del ambiente, pero probablemente no es grande. A las personas inmunosuprimidas no se les debe administrar la vacuna con virus vivos atenuados, pero sí puede aplicarse a otras personas en alto riesgo de complicaciones asociadas con la influenza, entre ellas las que tienen enfermedades subyacentes, mujeres embarazadas, personas con asma y adultos de 50 años de edad o más.

La vacuna con virus vivos atenuados únicamente se puede administrar por vía nasal y no debe administrarse por vía intramuscular, intradérmica o intravenosa. La vacuna se debe descongelar inmediatamente antes de su aplicación. Para ello se puede sostener brevemente en la palma de la mano o mantener en el refrigerador a $2-8{ }^{\circ} \mathrm{C}$ durante no más de 24 horas. Una vez descongelada, la vacuna no debe volverse a congelar. Se aplica mediante un atomizador de un solo uso que contiene $0,5 \mathrm{~mL}$ de la vacuna. La mitad, aproximadamente $0,25 \mathrm{~mL}$, se atomiza en la primera fosa nasal y se elimina la presilla que divide las dosis para administrar la segunda mitad en la otra fosa nasal. Aunque el vacunado estornude después de administrar la vacuna, no se debe repetir la dosis.

La vacuna de virus vivos atenuados se administra cada año según un esquema establecido (cuadro 4). Se puede administrar a personas con enfermedades agudas ligeras (por ejemplo, diarrea o infección ligera del árbol respiratorio superior con o sin fiebre). No obstante, si hay indicios clínicos de una congestión nasal que pueda impedir que la vacuna llegue a la mucosa nasofaríngea, se debe valorar la postergación de la administración hasta que se resuelva el cuadro clínico.

No se sabe si la administración simultánea de la vacuna con virus vivos atenuados y otras vacunas afecta a la seguridad o eficacia de alguna de ellas. En ausencia de datos específicos que indiquen que existen interferencias, es prudente atenerse a las recomendaciones de inmunización establecidas. Las vacunas de virus inactivados no interfieren con

\section{CUADRO 4. Esquema de administración de la vacuna viva} atenuada contra la influenza

- Los niños entre 5 y 8 años sin vacunación previa recibirán dos dosis de la vacuna con virus vivos atenuados con un intervalo de 6 a 10 semanas

- Los niños entre 5 y 8 años previamente vacunados con la vacuna con virus inactivados o con la vacuna de virus vivos atenuados deben recibir solo una dosis

- Las personas de 9 a 49 años deben recibir una dosis de la vacuna a base de virus vivos atenuados la respuesta inmunitaria a otras vacunas, ya sean de virus inactivados o vivos. Una vacuna de virus inactivados puede administrarse simultáneamente o en cualquier momento antes o después de la vacuna con virus vivos atenuados. Dos vacunas con virus vivos se deberán aplicar con un intervalo de cuatro semanas o más entre ellas siempre que sea posible.

La vacuna a base de virus vivos atenuados y el uso de medicamentos antivirales. No se ha estudiado el efecto de los medicamentos antivirales administrados junto con la vacuna de virus vivos atenuados. No obstante, como estos medicamentos reducen la replicación del virus de la influenza, no se debe administrar la vacuna a base de virus vivos atenuados hasta 48 horas después de haber suspendido el tratamiento antiviral y no se deben tomar medicamentos antivirales durante dos semanas después de recibir ese tipo de vacuna.

\section{CONSIDERACIONES FINALES}

Un buen programa de vacunación deberá combinar la información a la población y la educación de los trabajadores de la salud y de otros receptores potenciales de la vacuna. Además de elaborar un plan para identificar a las personas en riesgo de sufrir complicaciones, se debe contar con un sistema de aviso o convocatoria y de un mecanismo para calcular las tasas de vacunación. Es importante, además, tratar de eliminar todas las barreras administrativas y financieras que impiden el acceso a ella.

En general, las recomendaciones aquí expuestas difieren con respecto a las publicadas en el año 2004 en los siguientes aspectos:

- Se debe vacunar contra la influenza a todas las personas con trastornos que puedan comprometer la función respiratoria o el control de las secreciones o aumentar el riesgo de aspiración (disfunción cognoscitiva, lesiones de la médula espinal, convulsiones $\mathrm{u}$ otros trastornos neuromusculares).

- Se debe vacunar anualmente contra la influenza a todos los trabajadores de la salud. Las instituciones que utilizan los servicios de trabajadores de la salud deben esforzarse por suministrarles la vacuna a todos y por elevar al máximo las tasas de inmunización.

- Se deben aplicar las vacunas existentes (la de virus inactivados y la vacuna de virus vivos atenuados) a las personas indicadas, especialmente si se encuentran en alguno de los grupos de riesgo. Cuando el suministro de vacuna de virus inactivados es insuficiente, se fomentará el uso de la vacuna de virus vivos atenuados en las per- 
sonas indicadas, ya que ello puede ayudar a aumentar la disponibilidad de la vacuna de virus inactivados para los grupos de alto riesgo.

- Las cepas usadas en la vacuna trivalente para la temporada de 2005-2006 en los Estados Unidos de América poseen antígenos análogos a los de la cepa A/California/7/2004 (H3N2), la A/ New Caledonia/20/99 (H1N1) y la B/Shanghai/ 361/ 2002. En lugar del antígeno análogo al de la cepa A/California/7/2004 (H3N2), los fabricantes pueden usar el virus A/New York/55/2004, que es equivalente en términos antigénicos, y en lugar del antígeno análogo al de $\mathrm{B} /$ Shanghai/ $361 / 2002$, los virus B/Jilin/20/2003 o B/Jiangsu/ $10 / 2003$.

\section{SYNOPSIS}

\section{Preventing influenza: recommendations for the 2005-2006 season}

Influenza is a serious health problem worldwide due to the epidemics and pandemics that it periodically causes. The Advisory Committee on Immunization Practices (ACIP) of the United States of America recently published updated recommendations for influenza prevention and control for the 2005-2006 season. Many of these guidelines are of interest to the countries of the Region of the Americas, particularly those related to vaccination, which is the mainstay for preventing and controlling this disease. Various changes have been made in the recommendations that were published in 2004. First, the ACIP recommends vaccination against influenza for persons with any condition (e.g., cognitive dysfunction, spinal cord injury, seizure disorder, or other neuromuscular disorder) that can compromise respiratory function or make eliminating respiratory secretions difficult or that can increase the risk for aspiration. Second, the ACIP strongly recommends that all health care workers be vaccinated against influenza annually and encourages facilities that employ health care workers to vaccinate them by using approaches that maximize immunization rates. Third, the ACIP encourages the use of both available vaccines (inactivated and live, attenuated influenza vaccine (LAIV)) for eligible persons every influenza season, especially persons in recommended target groups. When inactivated virus vaccine is in short supply, the use of LAIV is especially encouraged, if feasible, for eligible persons (including health care workers) because such use might considerably increase the availability of inactivated virus vaccine for persons in high-risk groups. Fourth, the 2005-06 trivalent vaccine virus strains are A/California/7/2004 (H3N2)-like, A/New Caledonia/20/99 (H1N1)-like, and B/Shanghai/361/2002like antigens. For the A/California/7/2004 (H3N2)-like antigen, manufacturers may use the antigenically equivalent $A /$ New York/55/2004 virus, and for the B/Shanghai/361/2002like antigen, manufacturers may use the antigenically equivalent B/Jilin/20/2003 virus or B/Jiangsu/10/2003 virus.

Key words: influenza, vaccination, practice guidelines.

\section{REFERENCIAS}

1. Chin TDY. Influenza: epidemiology, prevention, and control. En: Epidemiology, the Internet and global health [Supercurso en línea]. Hallado en: http:/ / www. itt.edu/ super1/lecture/lec0652/index. $\mathrm{htm}$. Acceso el 9 de agosto de 2005.
2. Murphy BR WR. Orthomyxoviruses. En: Fields KD, Howley PM, eds. Fields virology. Philadelphia: Lippincott; 1996. Pp. $1397-445$.
3. Zimmerman RK. Recent changes in influenza epidemiology and vaccination recommendations. J Fam Pract. 2005;54 (1 Suppl):S1-8 . 